\title{
Organização Popular e Lutas Sociais na Venezuela: Um estudo de caso da Parroquia 23 de Enero
}

Mariana Bruce ${ }^{I}$

Resumo: Durante 40 anos, a Venezuela viveu sob um pacto oligárquico. A negligência do Estado em prover os serviços básicos para as classes populares aprofundou os laços de vizinhança nas comunidades que se desdobraram em organizações de base. Em Caracas, a Parroquia 23 de Enero, de caráter marcadamente popular, possui uma tradição de altos índices de organização anteriores ao chavismo que, por sua vez, foram alimentados e redefinidos com a proposta de construção de uma democracia participativa e protagônica a partir da eleição de Chávez e que, hoje, (re)atualiza suas lutas em um contexto pós-chavista de severa crise. Nesse interim, resgato a trajetória de alguns de seus moradores e ativistas com atuação na Parroquia para analisar as nuances desse processo e refletir sobre as dinâmicas materiais, objetivas e subjetivas que subjazem ao processo de transformações e disputas que acompanha o chavismo.

Palavras-chave: democracia, Venezuela, chavismo

\section{Popular Organization and Social Struggles in Venezuela: A case study of Parroquia 23 de Enero}

\begin{abstract}
For 40 years, Venezuela lived under an oligarchic pact. The state's neglect to provide basic services to the lower classes has deepened neighborhood ties in communities that have split into grassroots organizations. In Caracas, Enero Parish 23, which is markedly popular, has a tradition of high levels of organization prior to Chavism, which in turn were nurtured and redefined with the proposal to build a participatory and protagonist democracy from the election. Chavez, who today (re) updates his struggles in a post-Chavist context of severe crisis. In the meantime, I recall the trajectory of some of its residents and activists working in Parroquia to analyze the nuances of this process and to reflect on the material, objective and subjective dynamics that underlie the process of transformation and changes dispute that accompanies chavism.
\end{abstract}

Keywords: democracy, Venezuela, chavismo

Artigo recebido em 15/10/2019 e aprovado em 27/11/2019. 
MARIANA BRUCE

\section{Introdução}

Giovanni Levi ${ }^{\text {II }}$ destaca a importância de lidarmos com as trajetórias de maneira contextualizada. Se a biografia conserva sua especificidade, esta não poder ser lida sem mergulhá-la num contexto que lhe dá sentido. Ao mesmo tempo, através da biografia é possível observar de maneira privilegiada a dialética entre contexto e indivíduo, pois aquela apesar de exercer influência não pode também ser analisada de maneira absoluta, determinante. Existe uma margem de manobra, a liberdade de fazer escolhas e de transformar este mesmo contexto por parte do indivíduo.

Considerando estes aspectos, a trajetória de alguns moradores e ativistas da Parrqouia 23 de Enero, de Caracas, um bairro com histórica organização popular, nos ajuda a compreender o que subjaz às transformações trazidas pela eleição de Hugo Chávez Frias, em 1998, na Venezuela. Longe de ser um processo encerrado na figura do presidente, trata-se de uma resposta às escolhas feitas por milhares de venezuelanos ao longo dos 40 anos vividos sob o chamado Pacto Punto Fijo ${ }^{\text {III }}$.

Apesar de produto de um determinado contexto, a luta cotidiana desses indivíduos evidencia o lento processo de desgaste de um modelo oligárquico e repressivo e de construção de um espaço fértil que serviu de base para o movimento que Chávez representa. Trata-se de aspectos que, em certa medida, só podem ser apreendidos quando reduzida a escala de observação. Segundo Levi, esta opção metodológica "acentua as ações mais insignificantes e mais localizadas, para demonstrar as lacunas e os espaços deixados em aberto pelas complexas inconsistências de todos os sistemas" "IV .

É válido destacar que, apesar de não podermos traçar uma relação direta entre essas trajetórias específicas e o restante do país, definitivamente não se tratam de casos isolados. Desde o final do Pacto Punto Fijo, quando Margarita López Maya, tendo como base a ONG Provea, estima uma média de dois protestos de rua por dia em todo o país ${ }^{V}$, evidencia-se um quadro de expressiva efervescência social que, com a eleição de Chávez se redefine no sentido de se apropriar e colocar em prática um projeto de democracia participativa e protagônica e que, hoje, segue re-existindo ${ }^{\mathrm{VI}}$ nos marcos de uma nova conjuntura marcada pelo Governo de Nicolás Maduro, sucessor de Chávez, que enfrenta severa crise política, econômica e social ${ }^{\mathrm{VII}}$.

Em todos esses contextos, a Parroquia 23 de Enero é um território que se destaca pelo grau de organização e protesto popular, pelo número de consejos comunales e comunas formados durante o Governo Chávez e, na sequência, pelas lutas de resistência popular já no contexto do Governo Maduro. Por essa razão, compreender esse processo mais amplo tendo como enfoque um olhar mais específico sobre as ações de alguns moradores e ativistas deste território pode ser de significativa contribuição para desvendar os traços e características da organização popular e das lutas sociais na Venezuela, sobretudo durante o Governo Chávez, período no qual concentrei minha pesquisa de Mestrado que norteia este artigo ${ }^{\mathrm{VIII}}$. Assim, na sequência, primeiramente, vou apresentar a Parroquia 23 de Enero como o contexto maior onde se dão as trajetórias para, em seguida, analisa-las observando as dinâmicas da organização popular e das lutas sociais. Por fim, aponto alguns horizontes emancipatórios que se projetam.

\section{Prazer, 23 de Enero}




\section{ORGANIZAÇÃO POPULAR E LUTAS SOCIAIS NA VENEZUELA: UM ESTUDO DE CASO DA PARROQUIA 23 DE ENERO}

\section{MARIANA BRUCE}

Durante minha pesquisa para monografia de conclusão de curso sobre as Misiones Sociales na Venezuela, um dado chamava atenção: a significativa incidência deste projeto numa parroquia chamada 23 de Enero, localizada no Município Libertador, na zona oeste da região metropolitana de Caracas. Como as Misiones Sociales estão fortemente atreladas à organização popular, era possível deduzir que se tratava de uma região que contava com algum tipo de organização local. Outra evidência desse aspecto é que essa mesma parroquia já foi tema de vários documentários, dentre eles, Outra Maneira é Possivel... na Venezuela (2002) de Elisabetta Andreoli, Gabriele Muzio e Max Pugh, no qual foram feitas várias entrevistas com lideranças da região, além de um passeio pela comunidade; Venezuela Rising: A Lesson in Participatory Democracy (2006), dirigido por Jennifer Wager, que tem a parroquia como objeto central para analisar a mobilização popular em favor de Chávez no contexto do Referendo Revogatório de 2004; e o documentário Fuego Bajo el Agua (2009), de Lenin Brea e Nuria Vila, que fala sobre a história da parroquia, conhecida como zona roja pelos organismos de segurança do Estado por ser marcada por diversas lutas sociais. Chávez, em uma das aberturas de seu programa dominical Aló Presidente, assim classificou o bairro: "aquí vive el espíritu rebelde de un pueblo, el espíritu rebelde y eterno, la rebeldía perenne pudiéramos decir que radica, vive en estas montañas, en estos barrios del 23",IX.

No Mestrado, quando me propus a fazer uma discussão sobre a "democracia participativa e protagônica" no contexto do chavismo, a Parroquia 23 de Enero, mais uma vez, apareceu como um espaço interessante para se fazer um estudo de caso. Ao investigar sobre a região na internet, encontrei uma página chamada $E l 23$, no endereço www.el23.net, idealizada e gerenciada por Gustavo Borges, que define o sitio como "colectivo de comunicación visual y social nacido en las entrañas de un barrio de la capital Venezolana, que encontró en la unión de estas dos herramientas la llave para explicar la 'Retrospectiva de un Barrio latinoamericano"X. Nesse local, encontrei um pouco da história da parroquia e um rico conteúdo jornalístico sobre um conjunto de atividades políticas e comunitárias desenvolvidas pela comunidade, o que permitiu que tivesse acesso a um conjunto maior de informações sobre o bairro.

De igual forma, não faltam relatos de viajantes de todo o mundo - EUA, México, Argentina, Espanha, Noruega - falando sobre suas experiências no 23 de Enero com grande destaque para a organização popular existente e seus murais políticos que fazem referência às lutas revolucionárias e ao "espírito do 23" - data na qual o ditador Marcos Pérez Jiménez (1952-1958) foi derrubado depois de ampla mobilização popular. Che Guevara, Simón Bolívar, Simón Rodríguez, o movimento de Chiapas, Ali Primera e os chamados "combatientes del 23" (aqueles que morreram nas lutas sociais travadas na parroquia), compõem os vários murais distribuídos por toda a região.

Localizada na interseção do centro com a zona oeste, próxima ao Palácio Miraflores, a Parroquia 23 de Enero foi palco de intensos conflitos. Durante o período da IV $^{\text {a }}$ República (1958-1998) era conhecida como uma trincheira de resistência ao governo e, portanto, viveu anos de intensa repressão. Já nos tempos de Chávez, tornouse um dos mais simbólicos bastiões de sustentação do governo, a ponto do próprio presidente ter transferido sua zona eleitoral para o Liceo Manuel Palacio Fajardo, na Zona Central da parroquia e de ter realizado, pelo menos, quatro programas Aló Presidente na região ${ }^{\mathrm{XI}}$.

A existência de colectivos politicos, organizações armadas egressas da guerrilha urbana que se desenvolveu ao longo dos anos 60 e 70 e do combate ao narcotráfico nos 


\title{
MARIANA BRUCE
}

anos 80 e 90, torna a parroquia um dos lugares mais temidos pelo cidadão comum e, ao mesmo tempo, mais emblemático da luta popular.

Algumas estimativas apontam para uma população que varia de 200 a $500 \mathrm{mil}$ pessoas ${ }^{\mathrm{XI}}$ em seus $2,31 \mathrm{~km}^{2}$. A região possui várias entradas e saídas, o que a torna ainda mais estratégica do ponto de vista das lutas sociais. Por mais que tenha sido projetada com ruas largas por onde fosse possível transitar veículos militares, como tanques, esta "arquitetura de controle" não foi suficiente para impedir barricadas, queimas de pneus, de lixo, de veículos, durante as manifestações que ocorreram, principalmente, durante a $\mathrm{IV}^{\mathrm{a}}$ República - período no qual o Estado de Sítio foi proclamado 21 vezes.

Já durante o governo Chávez, com seus sistemáticos incentivos à formação de instituições de base nas comunidades mais pobres, a partir da defesa da construção de uma "democracia participativa e protagônica", a Parroquia 23 de Enero acabou se revelando como uma das que melhor respondeu ao chamado do Presidente, devido à sua longa trajetória de organização, o que faz da mesma um objeto interessante para se refletir sobre a dinâmica desde abajo das lutas populares na Venezuela antes e depois de Chávez ${ }^{\mathrm{XIII}}$. Nos tempos de crise que sucederam à morte de Chávez e ao governo de seu sucessor, Nicolás Maduro, a Parroquia segue como uma referência de luta e resistência popular.

\section{Histórias de luta e organização popular no 23}

César Rivas chegou à Parroquia 23 de Enero nos anos 70, depois de emigrar do povoado de Timotes, no Estado de Mérida. Era ainda garoto quando sua família se instalou no Barrio Sucre ${ }^{X I V}$. Rivas lembra que quando chegou havia vários grupos armados de esquerda. Juan Contreras, outro morador que participou de maneira mais direta da luta armada, destaca organizações como o MIR, Movimiento de Izquierda Revolucionário, divisão do então partido hegemônico Acción Democrática/AD, formado pela juventude radical que havia se juntado às Forzas Armadas de Liberación Nacional/FALN, braço armado do Partido Comunista e que, impulsionados pela vitoriosa Revolução Cubana, tentavam, através da guerrilha urbana, dar início a um processo revolucionário no país. Além destes, outras organizações também tiveram vida na parroquia, como o PRV, Partido de la Revolución Venezolana, o Bandera Roja/BR e o Organización de Revolucionários/OR. Os encapuchados ${ }^{X V}$ ou tupamaros $^{X V I}$, como ficaram conhecidos, faziam trabalhos comunitários e culturais, protagonizavam os enfrentamentos com a polícia e protestavam contra as mais diferentes problemáticas que afligiam aquela comunidade.

Segundo Contreras,

\begin{abstract}
Ese es el inicio de la lucha acá en el 23 de Enero. Y en principio peleando por los problemas que había: el tema de la represión, un servicio de agua permanente para el 23 de Enero, que los servicios públicos funcionaran, calidad de vida para nuestra comunidad y, luego, la visión de país que queríamos construir e ya hablábamos entonces de que el socialismo se conquistaba peleando y ese socialismo era un poco "saltar al cielo por asalto" que era conquistar el poder, tomar el poder, a través de las armas XVII
\end{abstract}

Além desse quadro de enfrentamento, o 23 de Enero, sobretudo os barrios, padecia com a carência de serviços ${ }^{\mathrm{XVIII}}$. Sensibilizado com tudo isso, Rivas, logo nos 


\section{MARIANA BRUCE}

seus primeiros anos, passou a se dedicar ao trabalho cultural dentro de seu setor, Barrio Sucre. Segundo o ativista, a cultura era utilizada como uma arma para dizer as coisas, para questionar o que estava incorreto, para exigir seus direitos, num período em que havia muita repressão e censura:

no teníamos la libertad que tenemos ahorita para decir las cosas. En esa época hablar de tema político crítico era difícil. Sin embargo, la cultura la ha tomado como arma para decir las cosas [...] Acuérdate que teníamos necesidad de agua, teníamos necesidad de seguridad, teníamos necesidad con todo que tenía que ver con los aspectos sociales de la vida diaria, pues, servicios básicos... y había que [luchar] por eso ${ }^{\text {XIX }}$.

Foi assim que nasceu no final dos anos 70 grupos culturais como "Churun-Meru", "Danza Canaima", "Curiara" e "Escuela Experimental Nuestro Barrio". Rivas, particularmente, sob a influência do pai que tocava quatro, engajou-se, principalmente, na via musical. Além dos aspectos políticos, através da música buscava-se construir uma identidade local e, ao mesmo tempo, resgatar as tradições dos diferentes povos que emigraram para a capital - mirandinos, andinos, orientais, etc.

Nos anos 1980, diante da crise neoliberal, estoura uma revolta popular sem precedentes na qual a população dos barrios desceu os morros e saqueou a capital e outras cidades próximas. O Caracazo de 1989 foi, assim, resultado de um conjunto de fatores: o empobrecimento da população em função de uma crítica recessão econômica e do esfacelamento das políticas públicas; da ausência de canais de mediação entre estas camadas alijadas de seus direitos e as instância de poder - os partidos e sindicatos foram se colocando cada vez mais a serviço das elites econômicas (ou mesmo se transformando em elites) e se viram envolvidos em escândalos de corrupção, por parte de seus dirigentes, perdendo sua legitimidade -; com a aplicação de políticas de cunho neoliberal, o que acabou por aprofundar ainda mais a crise econômica, sobretudo entre as camadas populares ${ }^{\mathrm{XX}}$; entre outros.

O governo reagiu através da decretação do estado de sítio e da repressão violenta. Daniel Hellinger, com base em relatos médicos, contabiliza um massacre de 1000 a 1500 pessoas em apenas três dias ${ }^{\mathrm{XXI}}$. Ainda assim, ao invés do movimento contestatório arrefecer, foram abertas as portas para a explosão de outros protestos de caráter callejero que marcaram os anos seguintes. É neste contexto que se localiza o índice levantado pela ONG Provea de, pelo menos, dois protestos por dia no país. Ao longo da década de 1990, houve, assim, uma intensa atividade de movimentos sociais na Venezuela, marcada pelo surgimento de novos atores sociais que queriam se fazer presentes no jogo democrático.

Segundo Rivas, à época do Caracazo, a Parroquia 23 de Enero foi um dos principais alvos da política repressiva do Estado:

el presidente Carlos Andrés y el Ministro [...] Italo del Valle Aliegro, bueno, la ordene fue masacrar al país, al pueblo, pues, y así se sucedió. Y esta parroquia no se escapó de esto, creo que fue una de las más... [reprimidas]. Y eran plomos por todos los lados. A nosotros nos tocó vivir un papel también importante. Y es así como dentro de todos esos acontecimientos llegamos a todo eso proceso que estamos viviendo hoy ${ }^{\mathrm{XII}}$. 


\title{
ORGANIZAÇÃO POPULAR E LUTAS SOCIAIS NA VENEZUELA: UM ESTUDO DE CASO DA PARROQUIA 23 DE ENERO
}

\section{MARIANA BRUCE}

Ainda como produto desse contexto amplo de contestações e desgaste do regime, em 1992, um grupo de militares tentaram fazer um Golpe de Estado para derrubar o presidente Carlos Andrés Pérez ${ }^{\mathrm{XXII}}$. Para Rivas, o golpe teve um outro significado

\begin{abstract}
ya habíamos pasado por acontecimientos desde aquél como el 27 de Febrero [Caracazo], una experiencia, bueno, que quedó para la historia que es el antecedente a lo que podemos llamar a lo que vivimos hoy, es allí donde nace las bases de lo que fue el Golpe, no el Golpe, diría que una Insurrección Militar, en todo caso - hay que estar claro en eso porque Golpe Militar es una cosa y una Insurrección Militar creo que es otra, que fue lo que pasó en el 04 de Febrero. Ya se había... en este caso, el presidente Chávez había participado de esto evento de 27 de Febrero, 27-28 de febrero de 1989, y se había levantado un movimiento militar allí porque se masacró el pueblo ${ }^{\text {XXIV }}$.
\end{abstract}

Sem dúvida, parte da construção desta perspectiva em relação ao Golpe de 1992 está relacionada ao momento vivido no presente por Rivas. Momento em que um daqueles militares acabou se tornando presidente da República e deu início a um processo de profundas transformações no país, o qual Rivas se sente parte. Porém, mesmo que naquele momento não estivesse tão clara a proposta daqueles militares, $o$ fato de seu líder, Hugo Chávez, depois de derrotado, ter tido a oportunidade de falar em rede nacional que seus planos de libertar o povo "ainda não tinham sido completados", abriu um novo horizonte de expectativas em torno de sua imagem. Expectativas que se converteram em uma proposta de governo que saiu vitoriosa nas eleições de 1998.

Um dos primeiros esforços do novo governo foi a convocação de uma Assembleia Constituinte para a assinatura de um novo Pacto Social. Produto de um amplo debate e ratificada em referendo, a Constituição Bolivariana de 1999 ampliou tanto o sentido de democracia quanto o de soberania do povo, ao introduzir a premissa da participação e do protagonismo popular na tomada de decisões.

Com isso, ganhou força um conjunto de organizações que tinha por princípio associar a gestão popular ao atendimento das demandas fundamentais da vida cotidiana, sobretudo entre as camadas mais pobres da população. A partir de 2002, quando o governo passou a ter o controle sobre a PDVSA e, com isso, passou a contar com os recursos da estatal para financiar os projetos, essas organizações ganharam um importante impulso ${ }^{\mathrm{XV}}$. Devido a sua longa trajetória de organização popular, o $23 \mathrm{de}$ Enero foi uma das parroquias que melhor respondeu ao chamado do Estado para se organizar.

Neste ano de 2002, o decreto 1.666 previa a formação dos Comités de Tierras Urbanas/CTUs que tinha por objetivo organizar os moradores dos barrios para obterem o título da propriedade da terra de graça - demanda histórica daquela população. No Barrio Sucre, César Rivas, ao lado de Aurora Volcem, senhor Avelino Maya, P. Eliseo e outros vizinhos foram eleitos pela Assembleia de Cidadãos e Cidadãs convocada pela então Junta Parroquial para liderarem os trabalhos no Comitê e viabilizar a entrega dos títulos.

Houve primeiramente uma reunião de esclarecimentos com membros da prefeitura (alcaldía), do Ministério Nacional de la Vivienda e da Junta Parroquial com a própria comunidade. Para Eliseo Pérez, um dos maiores ganhos dessa iniciativa foi ter podido entrar em contato com a comunidade, pois até então muitos ali não se conheciam.

Premio a ese decreto 1.666 es haber descubierto o descubrir que en todo los espacios de la vida cotidiana habían otras cosas que nosotros mismos no 


\title{
ORGANIZAÇÃO POPULAR E LUTAS SOCIAIS NA VENEZUELA: UM ESTUDO DE CASO DA PARROQUIA 23 DE ENERO
}

\section{MARIANA BRUCE}

sabíamos cómo era las necesidades que desde las puertas hacia adentro existían. O sea, pasamos a ser, nos convertimos en trabajadores sociales natos, psicólogos, sociólogos, todo eso sin ser titulado ingeniero de tierra ${ }^{\mathrm{XVI}}$.

O senhor Avelino Maya, já veterano em militância política na parroquia, fala da importância dessa iniciativa, pois teria transformado as necessidades individuais em necessidades coletivas e assegurado o primado da participação como via para resolver os problemas:

\begin{abstract}
cuando de los años 90 para tras, existía la necesidad. Y usted veía la necesidad como una necesidad individual. Cuando nuestro Presidente es elegido, esa necesidad individual se convierte en necesidad colectiva y es ahí donde nuestro Presidente ve la necesidad de investir en correctivos, aparatos, gestiones que permitieran que esas necesidades colectivas tuviesen una respuesta mediante la participación hecha por esa comunidad ${ }^{\mathrm{XXVII}}$.
\end{abstract}

Para Perez, graças a Constituição Bolivariana de 1999, que havia estabelecido o princípio da cogestão, foi possível demonstrar que o povo, sim, poderia gerir as políticas públicas dentro de suas comunidades.

la Constitución Nacional en el artículo 70 [...] se habla de lo que es la cogestión, la autogestión y la relación interinstitucional es de suma importancia para también administrar las cosas. [...]. Gracias a esta Constitución logramos realmente articular y esa articulación también con nuestro grado de consciencia puede mostrar que sí podemos, [...] lograr nuestros objetivos ${ }^{\text {XXVIII }}$

César Rivas chama atenção para o fato de que, apesar de haver intensa organização popular na Parroquia desde muito tempo antes de Chávez, era o Estado quem, ao fím e ao cabo, se responsabilizava pelos serviços públicos. Havia muita luta para conquistar direitos, mas quem executava os serviços eram os burocratas do Estado: "el Estado, pues, transitaba todo que tenía que ver con proyecto, todo que tenía que ver con arreglo, pero desde un punto de vista excluyente"XXIX . Por outro lado, a nova Constituição permitiu que aqueles setores que eram atuantes dentro das comunidades pudessem assumir, de fato, um papel protagônico para resolver seus problemas:

Portanto, com a própria comunidade a frente dos projetos, se aperfeiçoa o trabalho na medida em que esses moradores conhecem muito melhor as mazelas de seus territórios e a forma de resolvê-los do que os burocratas enviados pelo Estado.

Os membros do Comitê de Terras foram submetidos a talleres explicativos cursos para que aprendessem o básico de engenharia e outros conhecimentos técnicos para levarem a cabo o projeto. Uma das metas a serem cumpridas pelo Comitê era montar o cadastro da comunidade. Para tanto, teriam que entrar em todas as casas, fazer as medições dos terrenos, identificar ruas, escadas, becos, além de fazer um registro sócio-econômico.

Dentre as dificuldades encontradas, vale mencionar que muitos vizinhos não conheciam os membros do CTU e não os deixavam entrar em suas casas. Muitos não acreditavam que a titularidade seria entregue. Portanto, era preciso fazer um trabalho concomitante de convencimento e conscientização da importância do projeto.

Por outro lado, foi encontrado também muito apoio e com o cumprimento da promessa do Estado de entregar a titularidade, as ações do grupo foram reconhecidas, legitimadas e deram combustível para que, dessa iniciativa, se desenvolvessem outras. 


\section{ORGANIZAÇÃO POPULAR E LUTAS SOCIAIS NA VENEZUELA: UM ESTUDO DE CASO DA PARROQUIA 23 DE ENERO}

MARIANA BRUCE

Por exemplo, com o Golpe de Estado de 2002, houve o corte do serviço de gás. Aproveitando-se deste episódio, os mesmos membros do Comitê de Terras, que desde antes já alegavam a necessidade de fazer um projeto que garantisse o serviço de gás encanado para comunidade, com o apoio da PDVSA GAS, conseguiram superar muitos preconceitos, daqueles que não acreditavam que um serviço dessa monta pudesse ser feito e, hoje, o barrio conta com o serviço.

Da mesma forma ocorreu com o serviço de água, da onde surgiu a Mesa Técnica de Agua, outro Comitê formado por vizinhos que junto a Hidrocapital, empresa responsável pelo serviço, solucionou a problemática dentro do barrio. Trocaram todo o encanamento por um novo, além de garantirem serviço de água potável também: "hace 50 años practicamente nosotros peleamos con el gobierno porque son casas deterioradas, [con muchas] filtraciones. Con las Mesas de Técnica de Agua organizamos todo el servicio de agua"XXX.

Com as Misiones de saúde, foram os próprios membros do Comitê que receberam os cubanos. P. Eliseo hospedou os médicos cubanos em sua casa por um bom tempo até que se disponibilizasse um local para eles exercerem a atividade. O trabalho com o CTU foi muito importante para que eles pudessem se articular para receber a Misión Barrio Adentro no Barrio Sucre. A Misión Robinson, de alfabetização, foi também um sucesso. É valido dizer que a Parroquia 23 de Enero foi o primeiro território livre do analfabetismo do país, fruto de todo o trabalho de militância assumido por aquela população.

Portanto, a partir do trabalho do CTU e, com o apoio do Estado, garantindo todo o tipo de recursos para se executar os projetos, foi possível multiplicar organizações de base que tinham por objetivo solucionar as problemáticas da vida cotidiana. Esta premissa é atestada por Rivas quando fala que "los CTU fueron una herencia primogénita de este proceso. Esto es decir, le tocó asumir un papel duro, fuerte, [...] gracias a ese trabajo y producto de ese proyecto, pues, para decirte algo, fue importante para existir las otras organizaciones"XXXI.

Como um desdobramento de todas essas organizações é regulamentado, em 2006, depois de ampla consulta pública, a Ley Orgánica de los Consejos Comunales/CCs que é uma proposta de organizar todos esses comitês de trabalho em uma única instituição.

O objetivo, em linhas gerais, é mobilizar pequenos grupos locais, tendo como abrangência máxima 400 famílias (de 200 a 400 famílias nas cidades, a partir de 20 na área rural e 10 nas comunidades indígenas), e inserir a população na gestão das políticas de cada comunidade - processo que já vinha se desenvolvendo com os Comitês de Trabalho e as Misiones Sociales aludidos anteriormente.

Os conselhos, ao seguir os passos de formalização definidos na lei, têm a possibilidade de acesso a recursos públicos para serem investidos em suas localidades e, com isso, através de seus comitês de trabalho solucionar seus problemas cotidianos. A Lei já passou por várias adaptações. Grosso modo, com a Lei, os CCs são reconhecidos como pessoa jurídica o que facilita o acesso aos recursos através do Banco do Estado.

Os projetos de cada área são levados para votação na Assembleia de Cidadãos e Cidadãs, "instancia primaria para el ejercicio del poder, la participación y el protagonismo popular cuyas decisiones son de carácter vinculante para el consejo comunal respectivo"XXXII. É o espaço onde reside a soberania do conselho. Segundo Rivas, 


\title{
ORGANIZAÇÃO POPULAR E LUTAS SOCIAIS NA VENEZUELA: UM ESTUDO DE CASO DA PARROQUIA 23 DE ENERO
}

\section{MARIANA BRUCE}

\begin{abstract}
La Asamblea de Ciudadanos tiene un poder tal que la misma Constitución lo afirma y vinculante es decir que se toman decisiones con peso. Eso es el poder que está por cima del Consejo Comunal. Las Asambleas de Ciudadanos toman decisiones, quitan, ponen. Los Consejos Comunales nacen de la Asamblea de Ciudadanos ${ }^{\text {XXIII }}$
\end{abstract}

A Lei determina todas as condições para as eleições dos representantes, para a controladoria social e para a administração dos recursos. Todos os CCs devem ser registrados em instituições do Estado. "Los Consejos Comunales se registran en Fundacaracas, institución del Estado que se rige por normas que van en corresponsabilidad Estado y comunidad"XXXIV.

Com isso, com o aval de uma lei que regulamenta e estabelece os termos de organização nas comunidades, normatiza-se uma forma de participação e amplia a capacidade de ação dos moradores. Não nos deteremos aqui nas polêmicas que giram em torno desta instituição, nossa proposta é a de resgatar a partir da trajetória de Rivas e seus companheiros e companheiras a forma como foi implementado o $C C$ em sua região e sua visão de todo este processo.

Para Rivas, "los Consejos Comunales nacen como una estrategia nueva del Estado para fortalecer el poder popular". Trata-se de uma tentativa de desburocratizar os procedimentos para a execução dos projetos: "Traer los recursos delante de esas organizaciones para la aplicación en los proyectos que no tenga que pasar por esa cantidad de trabas que tenían". Além disso, é um reconhecimento de que as classes populares têm condições de gerir as políticas públicas para suas regiões: "el Presidente está claro: [...] las comunidades tienen la capacidad de administrar los recursos y gerenciar sus proyectos. Nosotros demostramos"XXXV .

O setor Barrio Sucre é formado por aproximadamente 520 moradias, unifamiliares, bifamiliares e multifamiliares, distribuídas em três ruas principais: calle Ayacucho, calle Miranda e calle Real La Cañada. À época da pesquisa entre 2010 e 2011, o Consejo Comunal da calle Real La Cañada estava dando seus primeiros passos para registrar-se. Segundo Rivas, "hay una cantidad de proyectos por ahí"XXXVI que vão desde a construção de uma quadra poli-esportiva na calle Ayacucho, até a gestão da recente Misión Barrio Nuevo, Barrio Tricolor de restauração e pintura de moradias.

Um dos maiores benefícios trazidos pelos $C C s$ é que eles ampliam o raio de ação dos antigos Comitês de Trabalho e a participação propriamente dita. Para registrar um $C C$ é preciso fazer um censo demográfico. Então, um grupo de moradores mais mobilizados é responsável por fazer um censo socioeconômico da sua área e uma história local. Assim, buscam conhecer sua própria história, visitam as casas, conhecem as pessoas, seus problemas, descobrem um mundo novo por trás das paredes de tijolos. Um mundo de problemas compartilhados. Cresce uma consciência de que existe uma coletividade ao redor e que, juntos, eles podem resolver os problemas que mais afligem suas vidas e trazer benefícios para a comunidade.

É, assim, considerando todos esses aspectos que as consequências de este processo aberto pela implementação de uma democracia participativa com forte protagonismo popular, nos permitem vislumbrar um conjunto de horizontes possíveis para o futuro.

\section{Para além de Chávez?}




\section{ORGANIZAÇÃO POPULAR E LUTAS SOCIAIS NA VENEZUELA: UM ESTUDO DE CASO DA PARROQUIA 23 DE ENERO}

\section{MARIANA BRUCE}

O que se percebe na Venezuela é um gradual processo de transformação da cultura política do país. Trata-se de um país onde a população jamais havia sido convocada a participar, onde a política, a esfera pública, não havia se constituído enquanto espaços legítimos de deliberação de ideias e aprovação de projetos. Política e cotidiano estavam dissociados, salvo nos dias de eleição, quando a cidadania terminava no ato de votar. Todos esses Comitês de Trabalho e, os CCs têm um importante papel de recuperar os espaços da esfera pública, (re)legitimando-os e ampliando-os para o interior das comunidades, através dos quais as pessoas comuns passam a ter poder deliberativo e decisório na instância que mais atingem as suas vidas.

Se, num dado momento, esta mobilização pode decorrer de um interesse oportunista de receber dinheiro do Estado ou de conseguir uma iluminação pública para rua ou um serviço de água potável, o espaço dos $C C s$ acaba por oferecer a possibilidade de que haja um desenvolvimento de consciência e de interesses em seu âmbito.

Por mais pragmático que possa ser um $C C$, ao se criar um espaço de convivência entre os vizinhos, os assuntos discutidos ali caminham paralelamente à vida política: se houve uma decisão polêmica do governo, se há um período de eleições ou de referendos, se há problemas de caráter mais amplo que os que se relacionam à realidade local, as reuniões permitem que estas opiniões encontrem um espaço comum para serem colocadas, questionadas e debatidas. Portanto, se, a priori, a função de um $C C$ é fundamentalmente atender às demandas locais, esses espaços podem ser potencializados para um sentido mais amplo que o original.

$\mathrm{O}$ fato de, na sequencia dessas ações, tenha-se partido para a construção das Comunas, com intuito de aumentar o raio de ação e de prerrogativas dos CCs é um sinal evidente desta premissa, ou seja, que, das demandas meramente locais, pode-se evoluir para questões políticas mais gerais - cujas consequências somente os próximos anos poderão esclarecer.

Mesmo após a morte de Chávez e diante das sucessivas crises enfrentadas pelo Governo Maduro, o 23 segue como um espaço estratégico de resistência à oposição que visa derrubar o Presidente e de articulação de organizações populares, inclusive armadas, que se recusam a abrir mão das conquistas alcançadas nos anos anteriores. Em tese, Maduro deverá se manter no poder até 2025, mas seu governo não pode ser entendido como uma extensão linear do chavismo, pois imprimiu características próprias ao processo. Carece ainda uma análise mais aprofundada dos efeitos dessas mudanças e desse novo contexto na base social que outrora sustentava o Presidente Hugo Chávez.

O que é possível inferir tendo como base o exposto até o momento é que transformar uma cultura política é um processo lento e gradual, de avanços e tropeços. Sem dúvida, existem muitos limites e desafios a serem enfrentados. O papel que se espera que os $C C s$ cumpram na gestão pública do país ainda está sujeito às intemperanças políticas, há problemas também em função da dependência dos recursos estatais e da centralização para a aprovação de projetos. Em que medida essa dependência do Estado impede maior democratização efetiva desses espaços de decisão política? Será que essas novas instituições teriam força e legitimidade para sobreviver sob um governo de oposição? Como se comportam efetivamente nesse cenário de crise durante o Governo Maduro?

Se a autonomia de um $C C$ a priori, é assegurada pela soberania da Assembleia de Cidadãos e Cidadãs, qual é a real interferência dos partidos políticos e de interesses clientelistas no interior dessas organizações? A presença de lideranças locais 


\section{ORGANIZAÇÃO POPULAR E LUTAS SOCIAIS NA VENEZUELA: UM ESTUDO DE CASO DA PARROQUIA 23 DE ENERO}

\section{MARIANA BRUCE}

carismáticas ou então de indivíduos articulados com redes clientelistas mais amplas ou partidárias pode influenciar a tomada de decisões da Assembleia de diferentes formas: pela retórica, pela troca de favores, pela coerção, pelo constrangimento ${ }^{\text {XXVII }}$. Será, então, que ao romper uma forma de clientelismo, os CCs possam vir a reestruturar outros, com novos sujeitos a frente ${ }^{\mathrm{XXXVIII}}$ ?

Para ampliar as capacidades e potencialidades destas instâncias é preciso consolidar uma cultura política de participação (em um país no qual a democracia sempre pareceu um conceito estranho para a maior parte da população) e uma consciência coletiva que sejam capazes de evitar o fantasma do burocratismo e da centralização das experiências socialistas do século XX que persistem como uma referência inegável. Se a aventura seguirá por este caminho ou não, precisaremos aguardar, mas seguiremos atentos.

\footnotetext{
${ }^{\mathrm{I}}$ Doutora em História Social pela Universidade Federal Fluminense (PPGH/UFF) com bolsa Cnpq e professora da rede pública e privada de ensino.

II LEVI, Giovanni. "Sobre a Micro-História". In: BURKE, Peter. A Escrita da História: Novas Perspectivas. São Paulo: UNESP, 1992.

III Em 1958, à raiz da queda do ditador Marcos Pérez Jiménez (1952-1958), na cidade de Punto Fijo, Estado de Falcón, foi assinado um pacto entre alguns dos principais partidos que haviam atuado na clandestinidade ou em oposição à ditadura - Acción Democrática/AD, Comité

de Organización Política Electoral Independiente/COPEI e, em menor escala, a Unión Republicana Democrática/URD. O pacto deu início a 40 anos de um regime bipartidário marcado pela repressão,
} corrupção e por uma democracia representativa aferida exclusivamente pelos votos.

IV LEVI, Op. Cit, p. 155.

V MAYA, Margarita López (coord.). Protesta y Cultura em Venezuela - los Marcos de Acción Colectiva em 1999. Buenos Aires: CLACSO, 2002, p. 9-13.

${ }^{V I} \mathrm{O}$ uso da expressão de Carlos Walter Porto Gonçalves tem por objetivo enfatizar como a resistência à modernidade colonial também significa um processo permanente de redefinição das próprias condições de existência de cada povo sem, contudo, abrir mão de sua condição de sujeito autônomo diante desses processos (Cf PORTO-GONÇALVES, 2002).

VII Desde a morte de Hugo Chávez, Nicolás Maduro enfrenta uma sucessão de crises. A queda na receita petroleira, o boom inflacionário, a crise de abastecimento, a guinada autoritária do Presidente, o recrudescimento da oposição com uma tentativa de golpe de Estado em 2019 envolvendo a autoproclamação de um novo Presidente são alguns dos capítulos que colocam em cheque a manutenção do legado do chavismo na Venezuela.

VIII Entre 2010 e 2011 realizei duas viagens à Venezuela e desenvolvi um trabalho de campo na Parroquia 23 de Enero de Caracas. Durante três meses, participei de várias reuniões de voceros, assembleias e de diversas atividades realizadas por diferentes Consejos Comunales na parroquia. Além dos depoimentos orais concedidos por seus protagonistas, coletei um arquivo audiovisual com mais de 40 horas de entrevistas com voceros de mais de 20 Consejos Comunales do 23 de Enero, e mais de 15 horas de gravações de reuniões, assembleias, palestras, encontros culturais e outras atividades.

IX CHÁ VEZ, Hugo. Aló Presidente, m 358, 24/05/2010 (transcrição), p. 1.

x BORGES, Gustavo. "El 23 de Enero: Retrospectiva de un Barrio Latinoamericano". In: www.el23.net. 2009 - consulta em 19/05/2011.

XI O programa $n^{\circ} 179$, na Plaza Cristo Rey, em 25/01/2004; o programa $n^{\circ} 227$, na sede do INCE (Instituto Nacional de Capacitación y Educación), em 03/07/2005; o programa n 359, em Monte Piedad, em 30/05/2010; e o programa n`369, no setor Flores de Catia, em 09/01/2011. Destaque também para o programa $\mathrm{n}^{\circ} 363$, quando o Presidente, via satélite, inaugurou uma Empresa de Propriedade Social (Empacotadora de Açúcar El Panal 2021), na Zona Central do 23 de Enero, em 09/08/2010.

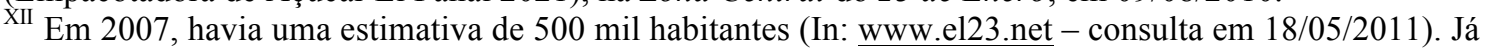
o Concejo Metropolitano de Planificación de Políticas Públicas/CMPP, estima em 200 mil (In: cmpp.gob.ve - consulta em 18/05/2011). 
XIII Destacar que a Parroquia 23 de Enero é considerada como um reduto chavista, não significa dizer que todos os seus moradores apóiam o governo. Ao contrário, há muitos anti-chavistas também - que, no entanto, encontram poucos espaços para se expressar.

${ }_{\mathrm{XIV}}$ Barrio é o equivalente a favela. Moradias construídas de maneira improvisada, sem qualquer auxílio do Estado.

${ }^{\mathrm{XV}}$ Encapuchados porque para manter a identidade protegida em tempos de dura repressão, esses jovens militantes utilizavam capuzes.

${ }^{\mathrm{XVI}} \mathrm{O}$ nome tupamaros para classificar os diversos agrupamentos políticos da região vem dos meios de comunicação que, nos anos 80, os comparavam com os tupamaros do Uruguai onde também houve uma intensa guerrilha urbana. Além disso, a presença de alguns remanescentes da guerrilha uruguaia no 23 de Enero contribuiu para que o nome se popularizasse.

XVII CONTRERAS, Juan. Licenciado em Serviço Social, aproxidamente 40 anos, morador do Bloque 19, setor La Cañada, Parroquia 23 de Enero. É fundador da Coordinadora Simón Bolivar. Entrevista realizada em 05/03/2010.

XVIII Os blocos de edifícios que compõem o cenário do 23 de Eneor já haviam sido projetados com serviço de gás e de água encanada, serviços estes que não existiam nos barrios, construídos no que seriam as áreas verdes dos edifícios, isto é, são os vários conjuntos de moradias populares construídas de maneira improvisada, sem auxílio do Estado.

XIX RIVAS D., César A. Licenciado em educação, aproximadamente 40 anos e morador do Barrio Sucre, Parroquia 23 de Enero. Foi fundador do Comité de Tierras Urbanas e Vocero de Cultura do CC ChurunMeru do Barrio Sucre. Entrevista realizada em março de 2010

${ }^{\mathrm{xx}} \mathrm{O}$ estopim que fez estourar a revolta foi o aumento do preço do combustível em $100 \%$ que, por sua vez, provocou o aumento ilegal das tarifas dos transportes coletivos, tendo sido retirado o benefício da meia-passagem para estudantes (GOTT, 2004: 74).

XXI ELLNER, Steve; HELlinger, Daniel (eds.). La Politica Venezoelana en la Época de ChávezClases, Polarización y Conflicto. Caracas: Nueva Sociedad, 2003, p. 48.

XXII RIVAS, Op. Cit.

XXIII No interior das Forças Armadas, desde a década de 70, houve a formação de um movimento organizado, tendo Chávez como um de seus protagonistas. O Movimiento Bolivariano Revolucionario 200 (MBR-200) surgiu do Exército de Libertação do Povo da Venezuela (ELPV) e tinha por objetivo promover algum tipo de sublevação. Foi o MBR-200 que esteve por trás do golpe frustrado de 1992. Depois do fracasso, o movimento desistiu da via armada. Nas eleições de 1993 apostaram numa campanha pela "não-participação" que cederia lugar, em 1998, à formação de uma coalizão de esquerda em torno da candidatura de Chávez. O MBR-200, que vinha angariando grande popularidade, transformou-se no Movimiento $V^{a}$ República (MVR) para disputar as eleições.

XXIV RIVAS, Op. Cit.

${ }^{x x v}$ Depois de uma tentativa de Golpe de Estado em 2002 e do Paro Petrolero no mesmo ano, Chávez teve a legitimidade para intervir na PDVSA - que havia se tornado um "Estado dentro do Estado" -, demitindo centenas de funcionários e reassumindo o controle sobre a estatal e seus recursos.

${ }_{\text {XXVI }}$ PÉREZ, Eliseo. Administrador, aproximadamente 40 anos e morador do Barrio Sucre, Parroquia 23 de Enero. Foi membro fundador do Comité de Tierras Urbanas do Barrio Sucre. Entrevista realizada em 07/03/2010.

XXVII MAYA, Avelino. Comerciante, aproximadamente 65 anos, morador do Barrio Sucre, Parroquia 23 de Enero. Foi membro fundador do Comité de Tierras Urbanas do Barrio Sucre e é Vocero de Finanzas do CC La Cañada. Entrevista realizada em 07/03/2010.

XXVIII PÉREZ, Op. Cit.

XXIX RIVAS, Op. Cit.

$\mathrm{xxx}$ VOLCAM, Aurora. Comerciante, aproximadamente 40 anos, moradora do Barrio Sucre, Parroquia 23 de Enero. Foi fundadora do Comité de Tierras Urbanas do Barrio Sucre. Entrevista realizada em 07/03/2010

XXXI RIVAS, Op. Cit.

XXXII LEY Orgánica de los Consejos Comunales/LOCC de 2006, artigo $5^{\circ}$.

XXXIII RIVAS, Op. Cit.

XXXIV Idem, ibidem.

xxxv Idem, ibidem.

XxxvI Idem, ibidem. 
XXXVII $\mathrm{O}$ constrangimento a que nos referimos pode ocorrer de diferentes formas. Uma delas é na hora do voto da Assembléia. Em muitos Consejos as eleições são abertas, o que pode inibir um indivíduo de votar contra uma decisão tirada em discussões anteriores.

xxxVIII DEL BÚFALO, Enzo. "Venezuela”. In: Los gobiernos progresistas en debate. Argentina, Brasil, Chile, Venezuela y Uruguay. CLACSO - Consejo Latinoamericano de Ciencias Sociales. PIT-CNT Instituto Cuesta Duarte: Buenos Aires, juio, 2006.

\section{FONTES}

\section{Entrevistas}

CONTRERAS, Juan. Licenciado em Serviço Social, aproxidamente 40 anos, morador do Bloque 19, setor La Cañada, Parroquia 23 de Enero. É fundador da Coordinadora Simón Bolivar. Entrevista realizada em 05/03/2010.

MAYA, Avelino. Comerciante, aproximadamente 65 anos, morador do Barrio Sucre, Parroquia 23 de Enero. Foi membro fundador do Comité de Tierras Urbanas do Barrio Sucre e é Vocero de Finanzas do CC La Cañada. Entrevista realizada em 07/03/2010.

RIVAS D., César A. Licenciado em educação, aproximadamente 40 anos e morador do Barrio Sucre, Parroquia 23 de Enero. Foi fundador do Comité de Tierras Urbanas e Vocero de Cultura do CC Churun-Meru do Barrio Sucre. Entrevista realizada em março de 2010.

VILLALOBOS, Mary. Comerciante, 40 anos e moradora do Barrio Sucre, Parroquia 23 de Enero. É Vocera de Economia Comunal do CC La Cañada. Entrevista realizada em 26/01/2011.

VOLCAM, Aurora. Comerciante, aproximadamente 40 anos, moradora do Barrio Sucre, Parroquia 23 de Enero. Foi fundadora do Comité de Tierras Urbanas do Barrio Sucre. Entrevista realizada em 07/03/2010.

\section{Outras}

CHÁVEZ, Hugo. Aló Presidente, m 358, 24/05/2010 (transcrição).

CONSTITUCIÓN de la República de Venezuela de 1961.

CONSTITUCIÓN Bolivariana de la República de Venezuela de 1999.

LEY Orgánica de las Comunas/LOC de 2010

LEY Orgánica de la Planificacion Publica/LOPP de 2002

LEY Orgánica del Poder Popular/LOPP de 2010

LEY Orgánica de los Consejos Comunales/LOCC de 2006.

LEY Orgánica de los Consejos Comunales/LOCC de 2009

SAFONACC. Planilha de gastos anuais para a Parroquia 23 de Enero (2008-2010). Texto Mimeo. 2011.

\section{Referências Bibliográficas}

BORGES, Gustavo. "El 23 de Enero: Retrospectiva de un Barrio Latinoamericano". In: www.el23.net. 2009 - consulta em 19/05/2011 
DEL BÚFALO, Enzo. "Venezuela”. In: Los gobiernos progresistas en debate. Argentina, Brasil, Chile, Venezuela y Uruguay. CLACSO - Consejo Latinoamericano de Ciencias Sociales. PIT-CNT Instituto Cuesta Duarte: Buenos Aires, juio, 2006.

ELLNER, Steve; HELLINGER, Daniel (eds.). La Politica Venezoelana en la Época de Chávez-Clases, Polarización y Conflicto. Caracas: Nueva Sociedad, 2003.

GOTT, Richard. À Sombra do Libertador - Hugo Chávez e a Transformação da Venezuela. São Paulo: Expressão Popular, 2004.

. Hugo Chávez y la Revolución Bolivariana. Madrid: Foca, 2006.

LANDER, Edgard. "El Estado y las tensiones de la participación popular en Venezuela”. In: OSAL. Año VIII No 22, septiembre, 2007.

LEVI, Giovanni. "Sobre a Micro-História". In: BURKE, Peter. A Escrita da História: Novas Perspectivas. São Paulo: UNESP, 1992.

. "Usos da Biografia". In: FERREIRA, Marieta de Moraes \& AMADO, Janaína (orgs). Usos e Abusos da História Oral. $8^{\text {a }}$ edição. Rio de Janeiro: FGV, 2009.

MAYA, Margarita López (coord.). Protesta y Cultura em Venezuela - los Marcos de Acción Colectiva em 1999. Buenos Aires: CLACSO, 2002.

PORTO-GONÇALVES, Carlos Walter. "Latifundios genéticos y r-existencia indígena". In Revista Chiapas, n 14, UNAM, D.F., México, p. 7-30, 2002. 